OPEN ACCESS

Edited by:

Huiming Zhang,

Shanghai Center for Plant Stress

Biology (PSC), China

Reviewed by:

Xingang Wang,

Purdue University, United States

Xin Deng,

Chinese Academy of Sciences, China

${ }^{*}$ Correspondence:

Albino Maggio

almaggio@unina.it

Specialty section:

This article was submitted to

Plant Abiotic Stress,

a section of the journal

Frontiers in Plant Science

Received: 12 May 2017

Accepted: 28 June 2017

Published: 18 July 2017

Citation:

Van Oosten MJ, Silletti S, Guida G,

Cirillo V, Di Stasio E, Carillo P,

Woodrow P, Maggio A and

Raimondi G (2017) A Benzimidazole

Proton Pump Inhibitor Increases

Growth and Tolerance to Salt Stress

in Tomato. Front. Plant Sci. 8:1220.

doi: $10.3389 /$ fpls.2017.01220

\section{A Benzimidazole Proton Pump Inhibitor Increases Growth and Tolerance to Salt Stress in Tomato}

\author{
Michael J. Van Oosten ${ }^{1}$, Silvia Silletti', Gianpiero Guida ${ }^{2}$, Valerio Cirillo', \\ Emilio Di Stasio', Petronia Carillo ${ }^{3}$, Pasqualina Woodrow ${ }^{3}$, Albino Maggio ${ }^{1 *}$ and \\ Giampaolo Raimondi ${ }^{1}$
}

${ }^{1}$ Department of Agricultural Sciences, University of Naples Federico II, Naples, Italy, ${ }^{2}$ National Research Council of Italy, Institute for Agricultural and Forestry Systems in the Mediterranean (CNR-ISAFoM), Ercolano, Italy, ${ }^{3}$ Department of Environmental, Biological and Pharmaceutical Sciences and Technologies, University of Campania "Luigi Vanvitelli", Caserta, Italy

Pre-treatment of tomato plants with micromolar concentrations of omeprazole (OP), a benzimidazole proton pump inhibitor in mammalian systems, improves plant growth in terms of fresh weight of shoot and roots by 49 and 55\% and dry weight by 54 and $105 \%$ under salt stress conditions (200 mM NaCl), respectively. Assessment of gas exchange, ion distribution, and gene expression profile in different organs strongly indicates that OP interferes with key components of the stress adaptation machinery, including hormonal control of root development (improving length and branching), protection of the photosynthetic system (improving quantum yield of photosystem II) and regulation of ion homeostasis (improving the $\mathrm{K}^{+}: \mathrm{Na}^{+}$ratio in leaves and roots). To our knowledge $\mathrm{OP}$ is one of the few known molecules that at micromolar concentrations manifests a dual function as growth enhancer and salt stress protectant. Therefore, OP can be used as new inducer of stress tolerance to better understand molecular and physiological stress adaptation paths in plants and to design new products to improve crop performance under suboptimal growth conditions.

Highlight: Omeprazole enhances growth of tomato and increases tolerance to salinity stress through alterations of gene expression and ion uptake and transport.

Keywords: benzimidazole, chemical priming, omeprazole, proton pump inhibitor (PPI), salt stress

\section{INTRODUCTION}

Soil salinization is a major problem for agriculture. It is estimated that by 2050 salinization will lead to up to $30 \%$ degradation of cultivated land (Rengasamy, 2006; FAO, 2011; Aragüés et al., 2015; Lal, 2015). The effects of soil and water salinity on plant growth and development have been well-documented. Excess of $\mathrm{Na}^{+}$and $\mathrm{Cl}^{-}$ions in proximity of the roots generate osmotic and ionic stress and activate signals inhibiting cell division and plant growth (Deinlein et al., 2014). Metabolic dysfunction and nutritional disorders associated with $\mathrm{Na}^{+}$and $\mathrm{Cl}^{-}$loading in plant tissues and organs translate in further growth reduction and eventually irreversible cell damage. Upon exposure to salt stress, the control of growth, ion and water homeostasis becomes an essential part of an adaptation program that helps resuming growth, albeit at a reduced rate (Maggio et al., 2006; Park et al., 2016; Van Oosten et al., 2016; Annunziata et al., 2017). During adaptation, ion movement 
through cellular compartments is essential to detoxify the cytoplasm and re-establish osmotic balance (Hasegawa, 2013; Ji et al., 2013; Mancarella et al., 2016). Plasma membrane and vacuolar $\mathrm{H}^{+}$-ATPases play a fundamental role in this physiological process since by generating active transport of proton $\mathrm{H}^{+}$across the membranes they create $\mathrm{pH}$ gradients and electrical potentials that drive transport of ions and molecules (including $\mathrm{NO}_{3}{ }^{-}, \mathrm{PO}_{4}{ }^{-}, \mathrm{K}^{+}, \mathrm{Na}^{+}$, sucrose, hexoses, and amino acids) across membranes (Pardo et al., 2006; Batelli et al., 2007; Deinlein et al., 2014). $\mathrm{H}^{+}$-ATPases can be activated/deactivated in response to many environmental cues such as abiotic stresses (Hasegawa, 2013). It occurs that salinization stimulates vacuolar $\mathrm{H}^{+}$-ATPase and $\mathrm{H}^{+}$-PPase activities which in turn facilitate tonoplast $\mathrm{Na}^{+} / \mathrm{H}^{+}$antiporter function and cytoplasm detoxification (Pardo et al., 2006; Ji et al., 2013). It has been shown that increasing cellular proton pump activity via co-overexpression of the vacuolar $\mathrm{H}^{+}$-pyrophosphatase gene AVP1 and the vacuolar $\mathrm{Na}^{+} / \mathrm{H}^{+}$antiporter gene AtNHX1, enhanced salt stress tolerance, most likely by potentiating ion compartmentalization functions (Shen et al., 2015). In contrast, cell treatment with vanadate (an inhibitor of the plasma membrane $\mathrm{H}^{+}$-ATPase) increases the $\mathrm{Na}^{+} / \mathrm{K}^{+}$ratio in plant tissues and enhances sensitivity to salinity (Li et al., 2014).

In animals, homologs of plant proton pumps operate through the $\mathrm{H}^{+} / \mathrm{K}^{+}$ATPase mechanism (Axelsen and Palmgren, 1998). Similar to plants, animal proton pumps working across membranes generate acidification of organismal compartments. For decades proton pump inhibitors (PPIs) have been successfully used to inhibit gastric acid secretion (McTavish et al., 1991). As matter of fact, benzimidazole based PPIs are common treatments used with gastro-esophageal reflux disease (GERD) and peptic ulcers (Baumann and Baxendale, 2013). In animals, omeprazole, the most common benzimidazole PPI, affects P-Type IIC ATPases. These P-Type IIC ATPases represent a large family of ATP driven transporters, which are responsible for moving ions across membranes. These include membrane $\mathrm{Ca}^{2+}$ pumps, $\mathrm{Na}^{+} / \mathrm{K}^{+}$transporters, and $\mathrm{H}^{+} / \mathrm{K}^{+}$transporters. Omeprazole is largely used as PPI that suppresses stomach acid secretion in the gastric mucosa (Wallmark, 1986; Shin et al., 2009). The specific inhibition of the P-Type IIC $\mathrm{H}^{+} / \mathrm{K}^{+}$ATPase located in the parietal cells is irreversible and specific. Plants are not known to possess P-Type IIC ATPases that transport $\mathrm{Na}^{+}$or $\mathrm{K}^{+}$, instead relying on the family of NHX-type $\mathrm{Na}^{+}$ and $\mathrm{K}^{+} / \mathrm{H}^{+}$antiporters for plasma membrane extrusion and compartmentation into the vacuoles and endosomes. Plants do possess P-Type IIA and III ATPases, primarily SERCA-like, which are not known to transport $\mathrm{Na}^{+}$or $\mathrm{K}^{+}$. SERCA-like ATPases show very low homology (approximately 25\%) to P-Type IIC ATPases that transport $\mathrm{Na}^{+}$or $\mathrm{K}^{+}$(Sweadner and Donnet, 2001). The SERCA-like ATPases are primarily endoplasmic reticulum transporters of calcium (Altshuler et al., 2012) and manganese (Mills et al., 2008). Plants also have P-Type III ATPases typically found in the plasma membrane, but none have been functionally characterized as $\mathrm{Na}^{+}$or $\mathrm{K}^{+}$transporters. While plants are not known to possess P-Type IIC ATPases that transport $\mathrm{Na}^{+}$or $\mathrm{K}^{+}$which are the target of omeprazole, we wanted to verify whether plant treatment with omeprazole may actually alter the transmembrane control of ion fluxes and disrupt plant tolerance to saline stress. In contrast to what we may have expected based on our current understanding of plant ATPases and plant responses to salt stress, here we demonstrate that tomato treatment with micromolar concentrations of omeprazole greatly enhanced plant growth and improved its tolerance to saline stress.

\section{MATERIALS AND METHODS}

\section{Plant Growth Conditions Hydroponic Experiment}

Tomato seeds (cultivar M82, accession LA3475) obtained from the Tomato Genetics Resource Center (TGRC ${ }^{1}$ ) were germinated in plates containing MS media and transplanted to a hydroponic system after 1 week when cotyledons were fully expanded. Air temperature $\left(\mathrm{T}_{\mathrm{a}},{ }^{\circ} \mathrm{C}\right)$, humidity $(\mathrm{RH}, \%)$, and solar radiation $\left(\mathrm{R}_{\mathrm{s}}, \mathrm{W} \mathrm{m}^{-2}\right)$ were acquired by a data logger (Spectrum Technologies, Plainfield, IL, United States). The average air humidity and temperature were $58 \%$ and $24^{\circ} \mathrm{C}$ during the day and $86 \%$ and $18^{\circ} \mathrm{C}$ during night-time, under short day conditions. Plants were grown in hydroponic solution containing: $1.5 \mathrm{mM} \mathrm{Mg}\left(\mathrm{NO}_{3}\right)_{2} \bullet 6 \mathrm{H}_{2} \mathrm{O}, 3.4 \mathrm{mM}$ $\mathrm{Ca}\left(\mathrm{NO}_{3}\right)_{2} \bullet 4 \mathrm{H}_{2} \mathrm{O}, 1 \mathrm{mM} \mathrm{KNO}, 1.8 \mathrm{mM} \mathrm{K}_{2} \mathrm{SO}_{4}, 1.5 \mathrm{mM}$ $\mathrm{KH}_{2} \mathrm{PO}_{4}$, and $14 \mathrm{mg} / \mathrm{L}$ Hidromix [Valagro, Atessa (Chieti) Italy]. Eight plants per treatment were grown in $4 \mathrm{~L}$ tanks with constant aeration. At 26 Days After Sowing (DAS), the first treatment of OP was added to the nutrient solution (1, 10, and $45 \mu \mathrm{M})$. Salt stress was initiated 36 DAS by adding $75 \mathrm{mM} \mathrm{NaCl}$ to salt treatments. At $42 \mathrm{DAS}$ the $\mathrm{NaCl}$ concentration was increased to $150 \mathrm{mM}$ and on $46 \mathrm{DAS}$ the $\mathrm{NaCl}$ concentration was raised to $200 \mathrm{mM} \mathrm{NaCl}$. Destructive harvest and biometrics were taken at 50 DAS (14 days of salt stress). Roots were separated from shoots in order to obtain their individual FW. To measure relative water content (RWC), shoots were transferred in deionized water for $24 \mathrm{~h}$ to induce maximum turgidity and weighed. Shoots and roots were dried for 3 days at $64^{\circ} \mathrm{C}$ and weighed individually. Root length was measured with a ruler; root area was measured using ImageJ as per Yoo et al. (2010).

\section{Soil Experiment}

Seedlings were germinated in previously stated growth conditions and when seedlings had four true leaves, they were transplanted into $5 \mathrm{~L}$ pots, filled with soil and fertilized after 7 days with Nitrophoska gold (Compo Agricoltura, Cesano Maderno, Italy). Then plants were equally divided into control and stress treatments, six replicates per treatment, and arranged in a randomized block design. Plants were well-irrigated for 30 days prior to start of the stress treatments. OP treated plants were watered with $500 \mathrm{~mL}$ of $1 \mu \mathrm{M}$ omeprazole at 36,50, and 68 DAS. At 60 DAS pre-stress physiological measurements were taken and then pots were saturated with $50 \mathrm{mM} \mathrm{NaCl}$ and the final salt concentration of $150 \mathrm{mM}$ was achieved at 68 DAS.

\footnotetext{
${ }^{1}$ http://tgrc.ucdavis.edu/
} 
At 72 DAS (14 days of salt stress), photos and physiological measurements were carried out.

\section{RNA Extraction and Quantitative RT-PCR}

Leaves of 7-week-old hydroponically grown plants (50 DAS, 14 DAST), treated with 1,10 , and $45 \mu \mathrm{M}$ OP, with 0 and $200 \mathrm{mM}$ $\mathrm{NaCl}$, were harvested and immediately frozen at $-80^{\circ} \mathrm{C}$. Leaves from the same treatment were mixed and three replicates per bulk were analyzed. $100 \mathrm{mg}$ of fresh leaf tissue per sample was homogenized with liquid nitrogen and extracted with $1 \mathrm{ml}$ of TRIzol (Life Technologies). First-strand synthesis was performed with a QuantiTect Reverse Transcription Kit (QIAGEN) using $1 \mu \mathrm{g}$ of total RNA. Real-time qPCR reactions, using $10 \mathrm{ng}$ of cDNA per reaction, two experiments, four replicates per experiment, were carried out on an ABI 7900HT qPCR detection system using Platinum SYBR Green qPCR SuperMix-UDG with ROX (Life Technologies). Each qRT-PCR experiment was repeated at least twice to confirm results. Primers were designed based on gene models and EST sequences available in GenBank ${ }^{2}$. All qRT-PCR primers were determined to be within 3\% efficiency of each other. Relative expression levels were calculated using EF1 $\alpha$ as an internal standard and the ${ }^{\Delta \Delta}$ Ct method for relative quantification. The primers used are listed in Supplementary Table S1.

\section{Ion Measurements}

Ions measurements were performed according to a procedure described by Carillo et al. (2011), with following modifications. $100 \mathrm{mg}$ of powdered dried material was suspended in $10 \mathrm{~mL}$ of MilliQ grade water (Milli-Q PLUS, Millipore, United States), and subjected to four freeze-thaw cycles by freezing in liquid nitrogen and thawing at $40^{\circ} \mathrm{C}$. Samples were centrifuged at $34000 \times g$ for $10 \mathrm{~min}$ and the clear supernatants were analyzed by ionexchange chromatography using a DX500 apparatus (Dionex, Olten, Switzerland) with an IONPACATC1 anion trap column (Dionex), an IONPAC-AG11 guard column (Dionex) and an analytical IONPAC-AS11 4-mm column (Dionex), fitted with an ASRSII 4-mm suppressor for anions (Dionex), and an IONPACCTC cation trap column (Dionex), an IONPAC-CG12A guard column (Dionex) and an analytical IONPAC-CS12A 4-mm column (Dionex), fitted with a CSRS 4-mm suppressor for cations (Dionex), with detection by a CD20 conductivity detector (Dionex), according to the manufacturer's instructions.

\section{Chl a Fluorescence Emission and Gas Exchange}

To determine chlorophyll a (Chl a) fluorescence, a LED light source with emission peaks centered at 465 (blue) and $635 \mathrm{~nm}$ (red) generated a PPFD equal to $1500 \mu \mathrm{mol}$ (photons) $\mathrm{m}^{-2} \mathrm{~s}^{-1}$ (90\% red, 10\% blue). A modulated fluorometer analyzer, Li-6400XT (Li-Cor Biosciences, Lincoln, NE, United States), was used to assess the fluorescence parameters. The measuring beam was set at intensity 5 (according to the instrument manual) with a modulation of $20 \mathrm{kHz}$. After the measurement of Chl a

${ }^{2}$ http://www.ncbi.nlm.nih.gov/genbank fluorescence emission at steady-state under light conditions, $\mathrm{F}^{\prime}$, the maximum fluorescence emission, $\mathrm{F}_{\mathrm{m}}{ }^{\prime}$, was assessed upon induction by a $0.8 \mathrm{~s}$ saturating light pulse at $6000 \mu \mathrm{mol}$ (photons) $\mathrm{m}^{-2} \mathrm{~s}^{-1}$ at $20 \mathrm{kHz}$. After that, actinic light was briefly switched off while a far-red light of $8 \mu \mathrm{mol}$ (photons) $\mathrm{m}^{-2} \mathrm{~s}^{-1}$ for $6 \mathrm{~s}$ was used to discharge the PSII to allow measurement of the minimum fluorescence emission under light conditions, $\mathrm{F}_{0}{ }^{\prime}$. Photochemical quenching $(\mathrm{qP})$ was calculated from the previously mentioned parameters. Net photosynthetic $\mathrm{CO}_{2}$ assimilation rate $(\mathrm{A}, \mu \mathrm{mol}$ $\left.\mathrm{m}^{-2} \mathrm{~s}^{-1}\right)$ and stomatal conductance of water vapor $\left(g_{\mathrm{s}}\right.$, mol $\mathrm{m}^{-2} \mathrm{~s}^{-1}$ ) were measured using a portable open-system gasexchange (Li-6400XT).

Measurements of photosynthetic rates (A) and stomatal conductance (gs) were taken at saturating light on well-exposed and fully expanded top leaves of six plants per treatment. Leaf chamber $\mathrm{CO}_{2}$ was set to $400 \mu \mathrm{mol} \mathrm{CO} \mathrm{CO}_{2}^{-1}$ air. Measurements were taken for each time point between 10:00 and 13:00 for the duration of the experiment (November 10th23rd, 2016). Gas-exchange parameters using the von Caemmerer and von Farquhar (1981) model were calculated by instrument software (Li-Cor, 2011). The effective quantum yield of PSII photochemistry in light-adapted leaves was calculated using: $\Phi_{\text {PSII }}=\left(F_{\mathrm{m}}{ }^{\prime}-\mathrm{F}^{\prime}\right) / \mathrm{F}_{\mathrm{m}}{ }^{\prime}$ (Genty et al., 1990). Anatomical analysis on a leaf area of $0.069 \mathrm{~mm}^{2}$ were performed as described in Yoo et al. (2010).

\section{Statistical Analysis}

Biometric measurements were statistically analyzed using the Student's $t$-test. Photosynthesis and gas exchange results were statistically analyzed using two-way ANOVA procedure with Sidak multiple comparisons test. Ion quantification was analyzed using a two-way ANOVA and Duncan's multiple range to determine differences between means $(P \leq 0.05)$. Ions for roots and shoots were statically analyzed in two separate analyses.

\section{RESULTS}

\section{Plant Growth}

In order to assess the potential for omeprazole to affect growth and salt tolerance, we conducted a hydroponic experiment at increasing OP concentrations. Measurements were taken to separate phenotypes of roots and shoots. Our results indicate that OP induces two specific phenotypes: (1) increased growth of roots and shoots and (2) increased tolerance and growth under high salt stress. Specifically, for growth we observed that $\mathrm{OP}$ works in a dose dependent manner (Figure 1). Low doses, $1 \mu \mathrm{M}$, stimulated significant increases in growth while a higher dosage either had no stimulatory effect $(10 \mu \mathrm{M})$ or, in the case of $45 \mu \mathrm{M}$, were inhibitory to growth. Application of OP at $1 \mu \mathrm{M}$ resulted in 49 and $48 \%$ increases in shoot FW and DW, respectively (Figure 1). The highest dose $(45 \mu \mathrm{M})$ inhibited growth of shoots and reduced FW and DW by 37 and $32 \%$, respectively (Figure 1). The stimulatory effect of OP was not limited to shoots; we also observed that $1 \mu \mathrm{M}$ stimulated root growth and biomass accumulation by increasing FW and DW of roots by 55 and 56\%, respectively. Higher concentrations, 

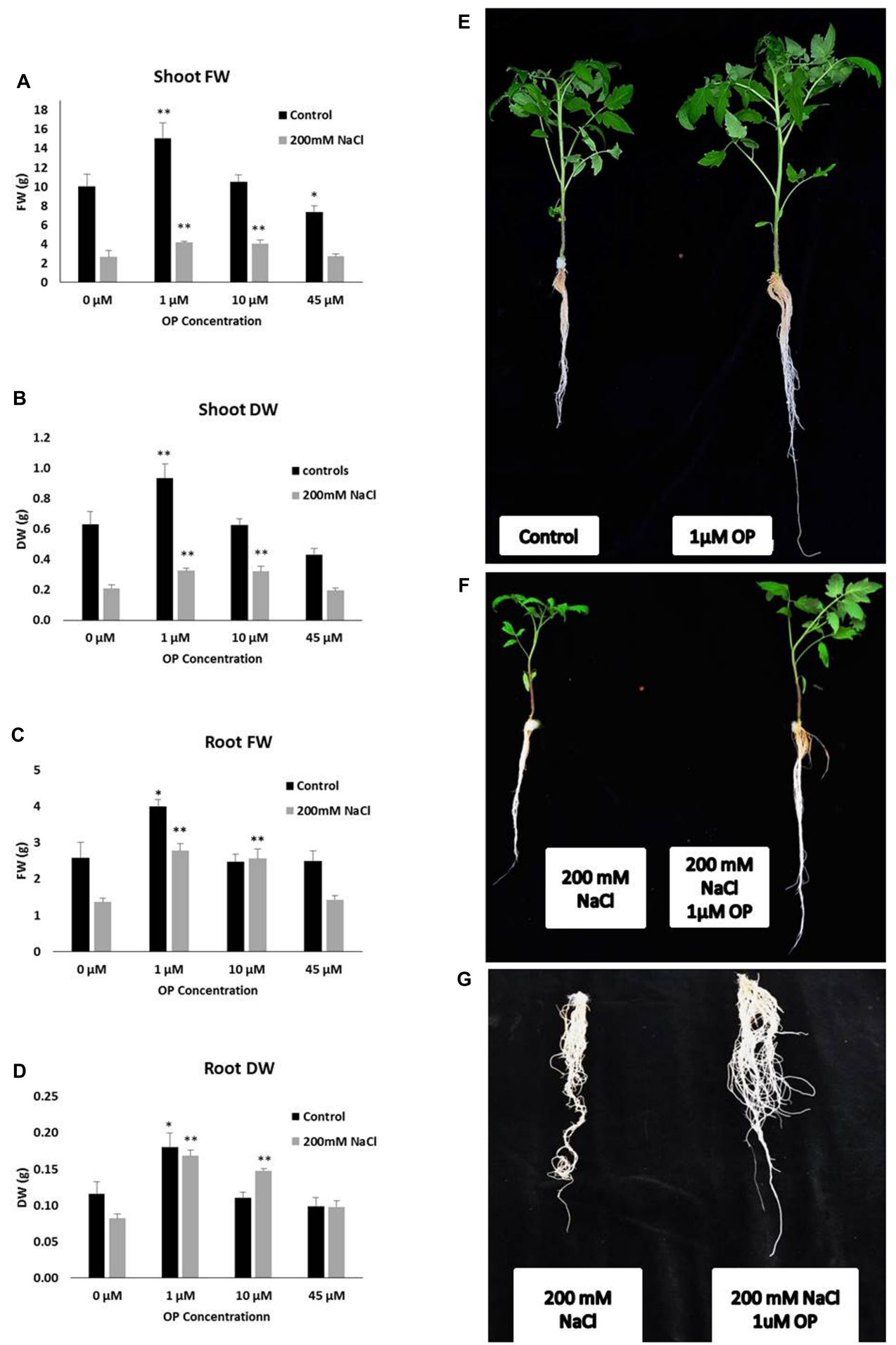

FIGURE 1 | Omeprazole (OP) enhances shoot and root growth of Solanum lycopersicum var. Red Setter plants under control and salt stress conditions. Photos (right panel series) show representative plants (E,F) or roots (G) treated with $1 \mu \mathrm{M}$ OP and controls, with and without $200 \mathrm{mM}$ NaCl. The left panel series indicates Shoot fresh weight (FW) and dry weight (DW) (A,B) and Root FW and DW (C,D). Plants were grown in a hydroponic solution containing 0 , 1 , 10 , and $45 \mu \mathrm{M}$ OP, with and without $200 \mathrm{mM} \mathrm{NaCl}$. Plants were harvested after 2 weeks of salt treatment (50 DAS, 14 DSS) and average shoot and root FW and DW was calculated. Values indicate average $\pm \mathrm{SE}(n=7)$. Single asterisks denote significant differences according to Student $(P<0.1)$ between untreated controls and OP treated plants, double asterisks denote $(P<0.01)$ between untreated controls and OP treated plants. 
10 and $45 \mu \mathrm{M}$, did not significantly affect root growth (Figure 1). In control growth conditions, low concentrations of OP did not increase root length significantly. However, at $45 \mu \mathrm{M}$ root length was severely inhibited, with a reduction of 53\% (Figure 2). While OP did not significantly increase the maximal lengths of roots, low doses greatly increased root mass. OP also had effect on later root branching resulting in changes to the overall root area.
Low concentrations of $1 \mu \mathrm{M}$ increased root area by $19 \%$. Again, $45 \mu \mathrm{M}$ had an inhibitory effect, decreasing root area by $44 \%$ (Figure 2).

\section{Salt Stress Tolerance}

The role of OP on salt stress tolerance was assessed in hydroponic culture. OP had significant effects on shoot growth
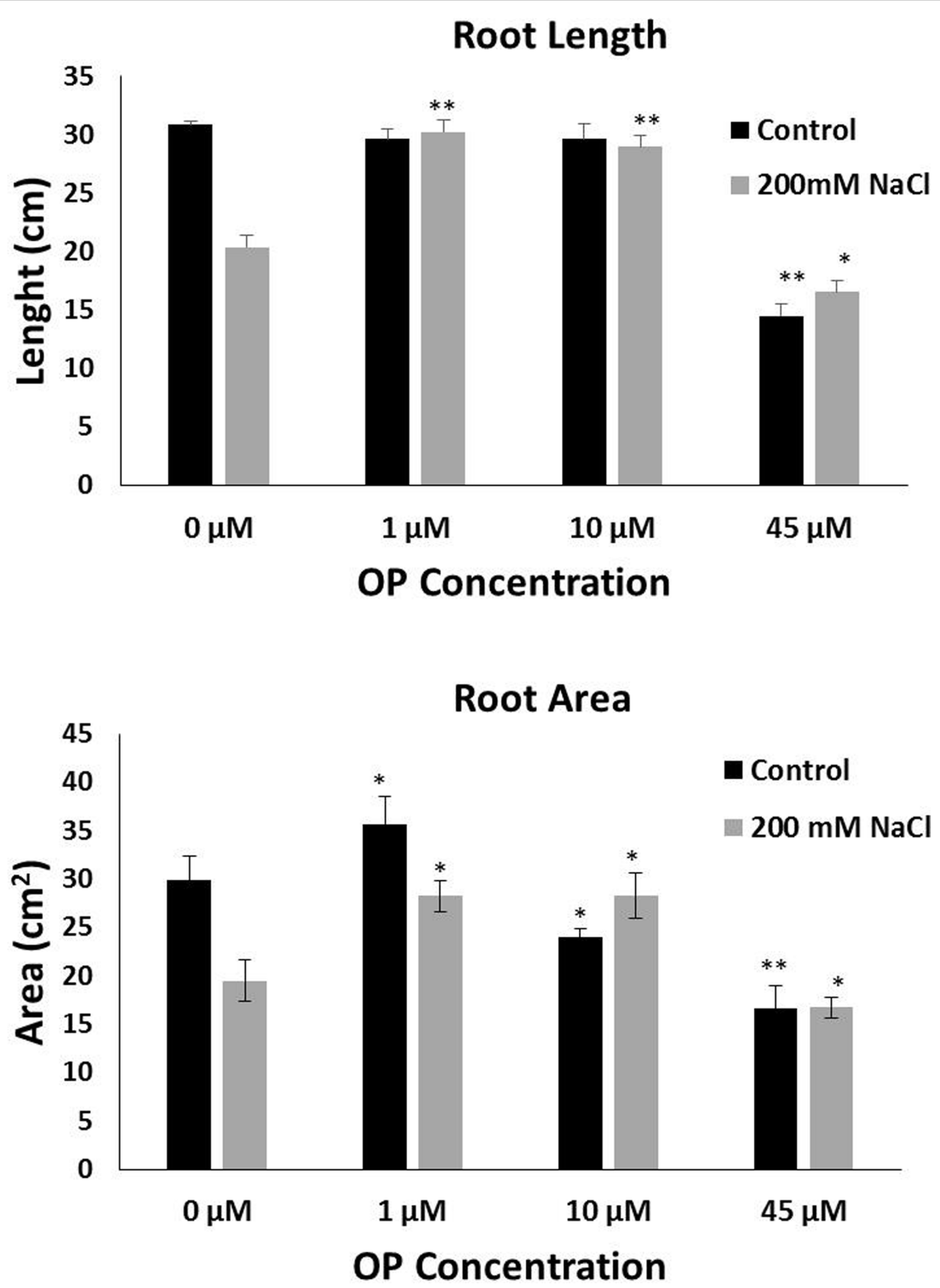

FIGURE 2 | Omeprazole enhances root growth of Solanum lycopersicum var. Red Setter plants under control and salt stress conditions. Average Root Length (top) and Average Root Area (bottom). Plants were grown in a hydroponic solution containing 0, 1, 10, and $45 \mu \mathrm{M}$ OP, with and without $200 \mathrm{mM}$ NaCl. Plants were harvested after 2 weeks of salt treatment (50 DAS, 14 DSS) and root length and area were measured. Values indicate average \pm SE $(n=7)$. Single asterisks denote significant differences according to Student $(P<0.1)$ between untreated controls and OP treated plants, double asterisks denote $(P<0.01)$ between untreated controls and OP treated plants. 
and remarkable effects on root growth in the presence of $\mathrm{NaCl}$ stress. Plants grown under severe salt stress, $200 \mathrm{mM} \mathrm{NaCl}$, and low concentrations of $\mathrm{OP}$ were able to maintain growth. Treatment with $1 \mu \mathrm{M}$ under $200 \mathrm{mM} \mathrm{NaCl}$ increased shoot FW and DW over untreated controls by 56 and 54\%, respectively (Figure 1). Similar results in shoots were observed with $10 \mu \mathrm{M}$ treatments and salt stress. The application of $45 \mu \mathrm{M}$ did not increase either of these shoot growth parameters under severe salt stress. Growth promotion under severe salt stress was more pronounced in roots. Both root FW and DW of $1 \mu \mathrm{M}$ OP treated plants was double (103 and 105\%, respectively) that of untreated controls under severe salt stress (Figure 1). While $10 \mu \mathrm{M}$ had no significant effect in control conditions, we observed increased tolerance in salt stress conditions. Salt stressed plants treated with $10 \mu \mathrm{M}$ demonstrated increases of $52 \%$ of FW and DW over untreated plants subjected to $200 \mathrm{mM} \mathrm{NaCl}$ (Figure 1). High concentrations of OP $(45 \mu \mathrm{M})$ did not induce significant gains under salt stress. Average root length for 1 and $10 \mu \mathrm{M}$ treated plants under salt stress was similar to controls and unstressed plants, showing no reduction in root length, while salt stress reduced average root length in untreated controls by one third (Figure 2). OP treated plants also showed increased root area under severe salt stress, with 1 and $10 \mu \mathrm{M}$ treated plants having an average of $45 \%$ more root area that untreated controls (Figure 2). Treatment with OP did not significantly alter RWC of leaves in either control or salt stressed plants $(90 \pm 0.04 \%$ for controls and $88 \pm 0.04 \%$ for OP treated plants and $68 \pm 0.03 \%$ for salt stressed plants and $71 \pm 0.01 \%$ for salt stressed plants treated with OP).

\section{Gas Exchange and Chl a Fluorescence Emission}

Gas exchange and Chl $a$ fluorescence emission were measured to assess direct effects of OP treatment on these physiological parameters. For this purpose, we conducted a second experiment with plants grown in soil. The second soil experiment was conducted using what was deemed to optimal concentration for $\mathrm{OP}(1 \mu \mathrm{M})$ and a $\mathrm{NaCl}$ concentration of $150 \mathrm{mM}$. Before stress imposition, $\mathrm{A}$, Net photosynthetic $\mathrm{CO}_{2}$ assimilation rate (A, $\mu \mathrm{mol} \mathrm{m} \mathrm{m}^{-2} \mathrm{~s}^{-1}$ ) and $\mathrm{g}_{\mathrm{s}}$ stomatal conductance of water vapor $\left(g_{\mathrm{s}}, \mathrm{mol} \mathrm{m}^{-2} \mathrm{~s}^{-1}\right)$ did not show any significant difference with respect to $\mathrm{OP}$ treatments, and they averaged 25.8 and $0.397 \mu \mathrm{mol} \mathrm{m} \mathrm{m}^{-2} \mathrm{~s}^{-1}$, respectively. In non-stress conditions, we did not observe any effect by $\mathrm{OP}$ on gas exchange or photosynthesis. Before salt stress imposition there was no statistical difference between untreated controls and OP treated plants where the average, $\Phi_{\text {PSII }}$ and $q P$ were 0.255 and 0.456 respectively.

After imposition of salt stress with $150 \mathrm{mM} \mathrm{NaCl}$, we observed no significant differences for $\mathrm{A}$ and $\mathrm{g}_{\mathrm{s}}$ under salt stress conditions in soil, between OP treated plants and controls (Supplementary Figure S1). However, we did observe a protective effect on photosystem integrity in $1 \mu \mathrm{M}$ OP treated plants subjected to salt stress. Both $\varphi_{\text {PSII }}$ (quantum yield of photosystem II) and $q P$ (photochemical quenching) were significantly affected by salt stress and OP (Figure 3). After 14 days of salt stress $\Phi_{\text {PSII was }}$
0.124 and $q P 0.279$ in OP treated plants, 37 and $43 \%$, respectively, higher than untreated controls (Figure 3). Stomatal Index and Stomatal Density were found to be similar between OP treated plants and controls (data not shown).

\section{Ion Profile of Omeprazole Treated and Salt Stressed Plants}

To better understand the mechanisms that OP affects to increase growth and tolerance to salt stress, tissue ion concentrations were profiled in all hydroponic treatments. OP altered the ion accumulation of tomato plants in control conditions and under severe salt stress. In unstressed conditions, OP increased $\mathrm{K}^{+}$ accumulation in roots treated with $1 \mu \mathrm{M}$ (Figure 4); however, it did not increase $\mathrm{Na}^{+}$accumulation. OP did affect the $\mathrm{Na}^{+}: \mathrm{K}^{+}$ ratio of salt stressed leaves and roots. The root $\mathrm{Na}^{+}: \mathrm{K}^{+}$ratio of roots under salt stress was reduced by 12,23 , and $35 \%$ in 1, 10, and $45 \mu \mathrm{M}$ OP treated plants, respectively (Figure 4). Calcium accumulation was also affected by OP treatment. In shoot, lower OP concentrations, 1 and $10 \mu \mathrm{M}$, decreased shoot calcium concentration significantly. Interestingly, $45 \mu \mathrm{M}$ OP increased calcium concentration in roots and shoots. Root chloride accumulation was observed to be elevated in roots of plants treated with OP when compared to controls only under stress condition. Treatment with OP was observed to increase nitrate content of roots at 1 and $45 \mu \mathrm{M}$. OP treatment with salt stress did not result in any significant increase in nitrate accumulation (Figure 4).

\section{Gene Expression}

Gene expression analysis was used to characterize the downstream mechanisms affected by OP that resulted in improved growth and salt tolerance in hydroponically grown tomatoes (Figures 5-7). We looked at three general categories of genes: ion transporters, stress signal transduction and osmotic response components, genes involved in antioxidant and photosynthetic systems. Gene expression was evaluated in roots and shoots. We found that OP treatment affected a number of genes in non-stress conditions and augmented responses of numerous key genes involved in salinity stress responses and adaptation.

For ion accumulation, exclusions and transport, we selected a few ion transporters known to play key roles in responses to salinity: the plasma membrane $\mathrm{Na}^{+}$antiporter SISOS1, two tonoplast located $\mathrm{K}^{+}$antiporters, SINHX1 and SINHX2 and the $\mathrm{Na}^{+}$transporter SIHKT1.1 (Figure 5). SISOS1 was significantly upregulated in all OP treatments, with augmented expression over untreated controls under salt stress in roots and shoots (Figure 5). This may have likely contributed to the lower $\mathrm{Na}^{+}: \mathrm{K}^{+}$ratio seen in the ion analysis. For the two tonoplast located potassium antiporters, SINHX1 and SINHX2, which also mediate critical functions, including turgor maintenance, stomatal function and ion homeostasis under hyperosmotic stress (Zhang and Blumwald, 2001; Pardo et al., 2006), both genes were significantly upregulated under $1 \mu \mathrm{M}$ OP treatment with increased expression over controls under salt stress (Figure 5). We also analyzed the expression pattern of HKT transporters, 

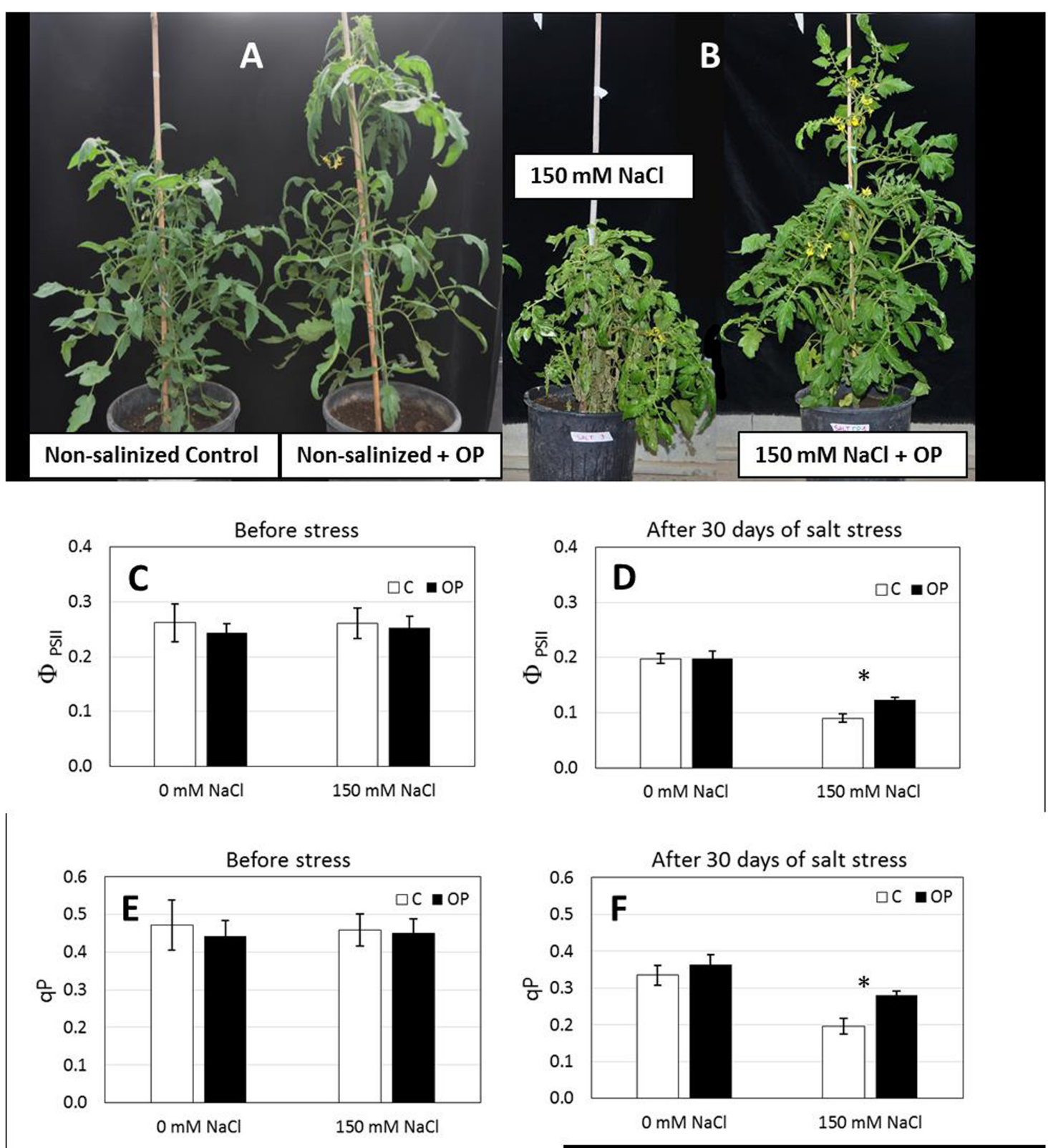

FIGURE 3 | Omeprazole enhances growth and tolerance to salt stress of Solanum lycopersicum var. Red Setter plants. Plants were grown in soil, unsalinized or salinized with $150 \mathrm{mM} \mathrm{NaCl}$ and irrigated with 0 and $1 \mu \mathrm{M}$ OP. Photos (A,B) of representative plants were taken after 2 weeks of salt treatment (72 DAS, 14 DSS) and efficiency of Photosystem II $\left(\Phi_{\mathrm{PSI}}, \mathbf{C}, \mathbf{D}\right)$ and photochemical quenching (qP, E,F) was measured. Values indicate average \pm SE $(n=6)$. Single asterisks denote significant differences according to Student $(P<0.01)$ between untreated controls and OP treated plants.

which play an important role in limiting the influx and subsequent accumulation of sodium into the shoot as well as sodium loading into root xylem (Asins et al., 2013; Ali et al., 2016). HKT1.1 expression in shoots was higher in OP treated plants compared to untreated controls in non-stress and salinity stress conditions (Figure 5). In roots, we found that OP treatment decreased SlHKT1.1 expression slightly in non-stress conditions and remarkably under salt stress. Decreased expression of HKT1 transporters may have significantly reduced sodium entry into roots, protecting them from ionic stress. Furthermore, HKT1 expression increased in salt stressed shoots. This may have favored sodium recirculation into the xylem, a function that coupled with decreased uptake and loading in roots could be a key role OP plays in salt tolerance. This result is consistent with a reduced $\mathrm{Na}^{+}: \mathrm{K}^{+}$ratio found upon OP treatment. In non-stress conditions, treatment with OP increased the nitrate content of roots and moderately in shoots (Figure 4). In order to link the observed nitrate accumulation profile with gene functions, we 

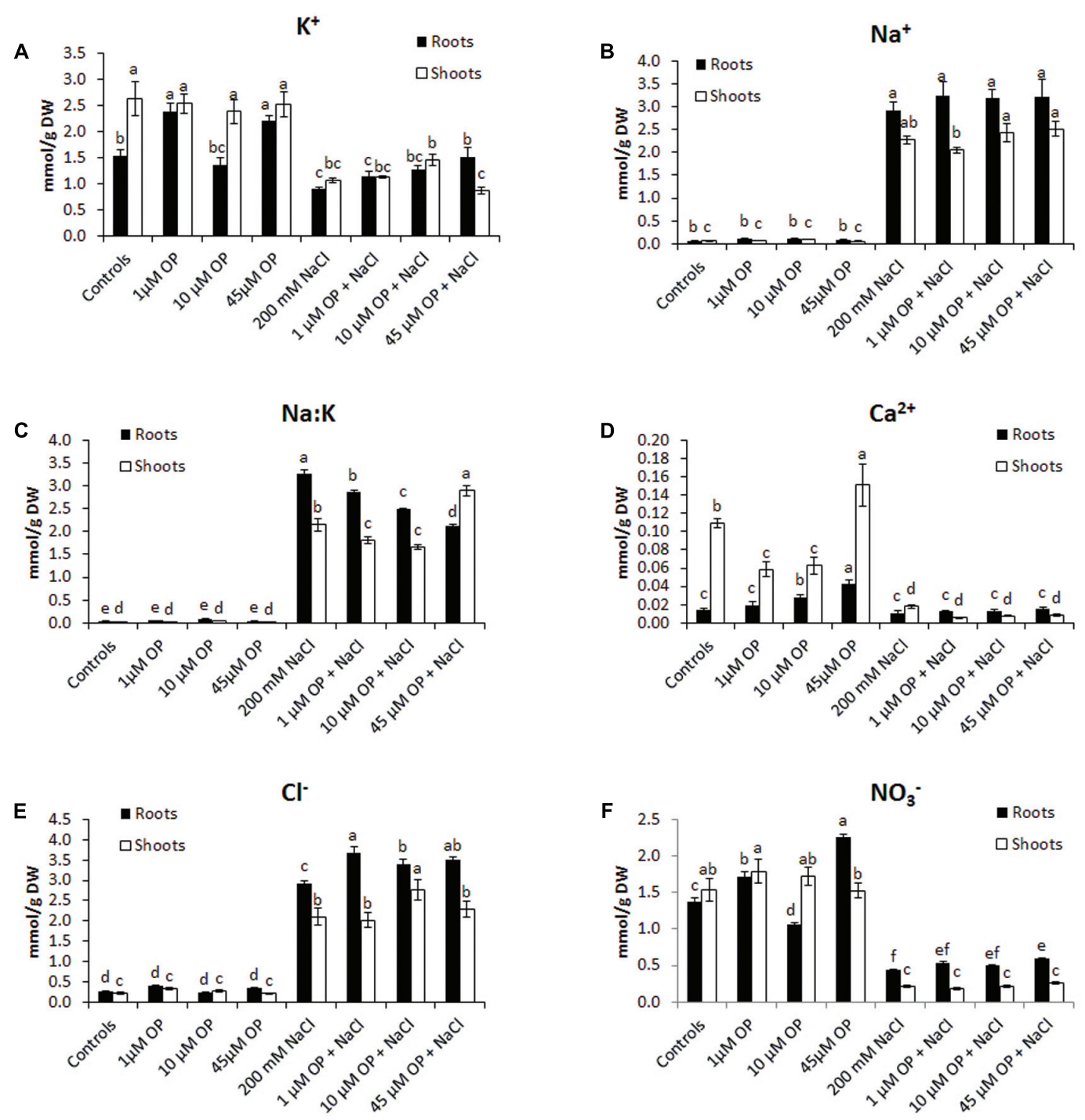

FIGURE 4 | lon profiles of Solanum lycopersicum var. Red Setter plants treated with omeprazole. Plants were grown in a hydroponic solution containing 0, 1, 10, or $45 \mu \mathrm{M}$ OP, with and without $200 \mathrm{mM} \mathrm{NaCl}$. Plants were harvested after 2 weeks of salt treatment (50 DAS, 14 DSS) and used for ion analysis. Values for $\mathrm{K}^{+}$(A), $\mathrm{Na}^{+}(\mathbf{B}), \mathrm{Na}: \mathrm{K}$ ratio $(\mathbf{C}), \mathrm{Ca}^{2+}(\mathbf{D}), \mathrm{Cl}^{-}(\mathbf{E})$, and $\mathrm{NO}^{-} \mathbf{( F )}$ are shown. Values indicate average $\pm \mathrm{SE}(n=6)$. Different letters indicate significant differences at $P<0.05$ between an OP treated sample and the corresponding untreated control.

examined the gene expression of the bidirectional transporter SINRT1.1 responsible for uptake and transport of nitrate (Jossier et al., 2010). Expression of SINRT1.1 was upregulated in OP treated plants, in roots and shoots, under non-stress conditions. We also observed higher SINRT1.1 expression in salt stressed plants with OP application although no significant increases in nitrate content were detected under stress conditions.

With respect to stress signal transduction components, we analyzed the expression of an ABA biosynthesis gene, SINCED, and an ABA catabolism gene SlCYP707A3. We found that OP treatment decreased SINCED expression in roots and shoots in non-stress conditions. Interestingly, SINCED was induced upon salt stress, yet OP treatment caused an opposite response compared to what was observed in control plants (Figure 6).
Specifically, in contrast to control plants, shoot expression of SINCED was elevated over untreated controls in shoots under salt stress while root expression was significantly reduced. SlCYP707A3 expression was highly dysregulated under $1 \mu \mathrm{M}$ OP treatment. While shoot expression was less than a third of controls, root expression was nearly three times that of untreated roots. Under salinity stress and OP treatment, expression of SlCYP707A3 was not downregulated. To better explain the expression pattern of $\mathrm{ABA}$ related genes, we examined the expression of SILEA a highly inducible marker in response to abiotic stress (Iovieno et al., 2016). While SlLEA was induced in salt stress conditions, it was less highly upregulated in the roots of OP treated plants under salt stress. This seems to correlate with decreased ABA signal transduction in the roots. In salt 

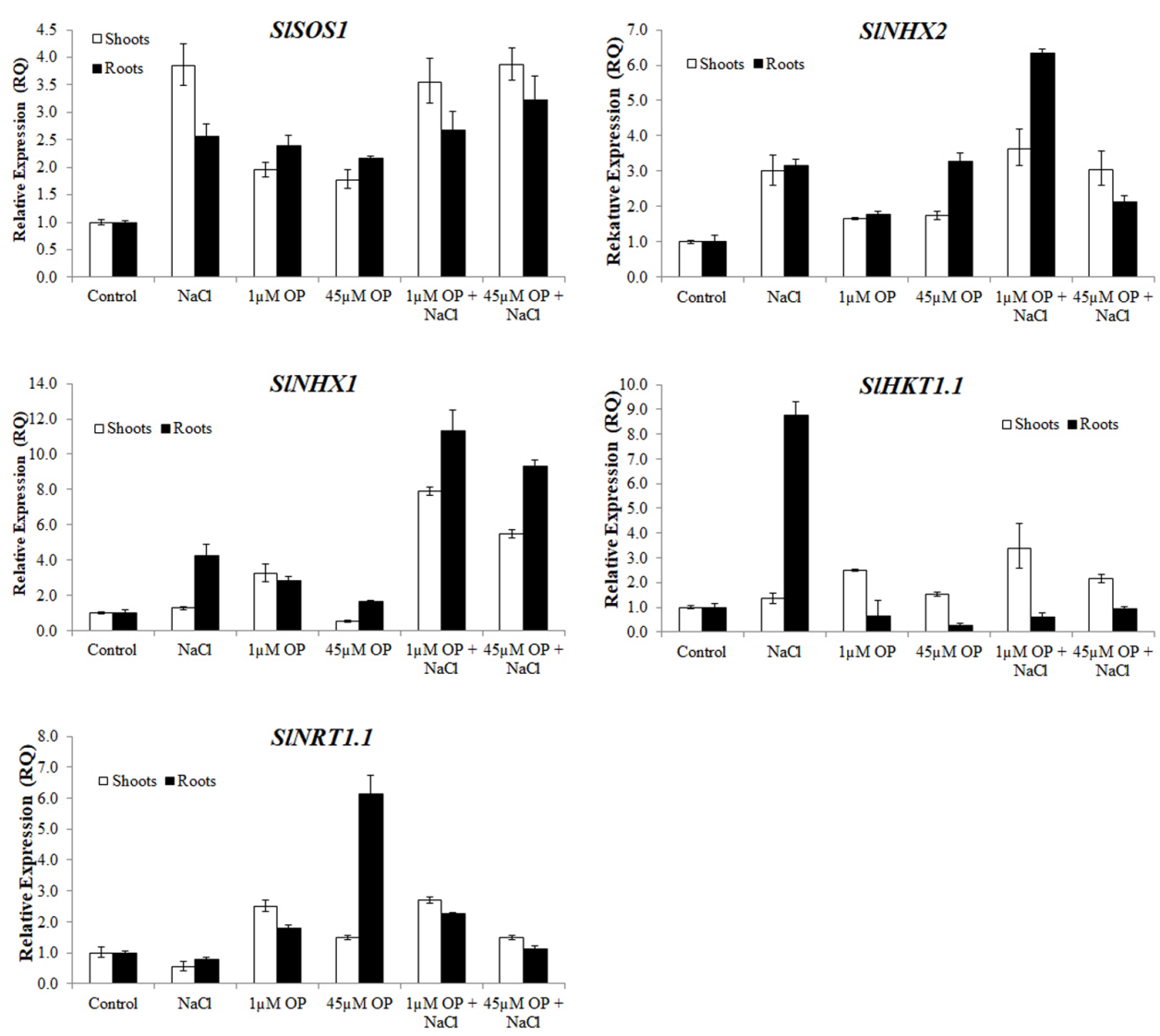

FIGURE 5 | lon transporter gene expression in plants treated with omeprazole. Plants were grown in a hydroponic solution containing 0,1 , and $45 \mu \mathrm{M}$ OP, with and without $200 \mathrm{mM} \mathrm{NaCl}$. Samples for qRT-PCR were harvested after 2 weeks of salt treatment (50 DAS, 14 DSS) and harvested for ion analysis. Values indicate average $\pm \mathrm{SD}(n=3)$.

stressed shoots treated with OP, SILEA demonstrated drastic upregulation, 10-fold higher than in untreated salt stress controls.

We also examined the antioxidant machinery and osmotic adaptation expression profiles of genes associated to ascorbate and proline biosynthesis. The cytosolic ascorbate peroxidase, SlAPX2, was highly upregulated in shoots and roots of salt stressed plants. In OP treated plants under salt stress, root SlAPX2 expression was highly induced, compared to salt stress controls, indicating a more robust ROS scavenging response induced by OP. With respect to proline and osmotic stress response, while expression of pyrroline-5-carboxylate synthetase, SIP5CS was not significantly altered in OP treated controls, it showed increased expression in salt stressed roots and shoots. Expression of the genes encoding for the catabolic pyrroline-5carboxylate dehydrogenase, SIP5CDH, showed a similar pattern in shoots of OP treated plants under salt stress. This may have contributed to a differential accumulation of proline in the roots and shoots.

The last set of genes we examined were those involved in the protection of the photosynthetic system. Expression levels of the tomato photosystem II reaction center psb28-like protein (PSII) were significantly upregulated under low concentrations of OP. These increases were also observed in OP treated plants under severe salt stress (Figure 7). In the leaves of OP treated plants under salt stress we found significant upregulation of the tomato catalase gene, SlCAT1 (Figure 7). High SlCAT1 expression levels have been found to enhance salt stress tolerance by reducing photoinhibition from damage to the photosystem by $\mathrm{H}_{2} \mathrm{O}_{2}$ (AlTaweel et al., 2007). We also examined the tomato homolog of FtsH, an ATP-dependent protease that plays a key role in degradation and repair of photosystem II (Kato et al., 2009; Sun et al., 2010). Expression of SIFTSH was below detectable thresholds in controls and OP treated plants. However, salt stress induced SIFTSH expression with an even greater upregulation under salt stress and OP treatment.

\section{DISCUSSION}

\section{Omeprazole Improves Plant Growth and Salt Stress Tolerance}

In this work we demonstrated that by feeding tomato roots with hormonal concentrations of omeprazole, a benzimidazole PPI in animal systems, we can significantly improve plant growth and ability to tolerate saline stress. OP treatment with $1 \mu \mathrm{M}$ increased shoot FW by $49 \%$ and DW by $48 \%$. FW of roots was 

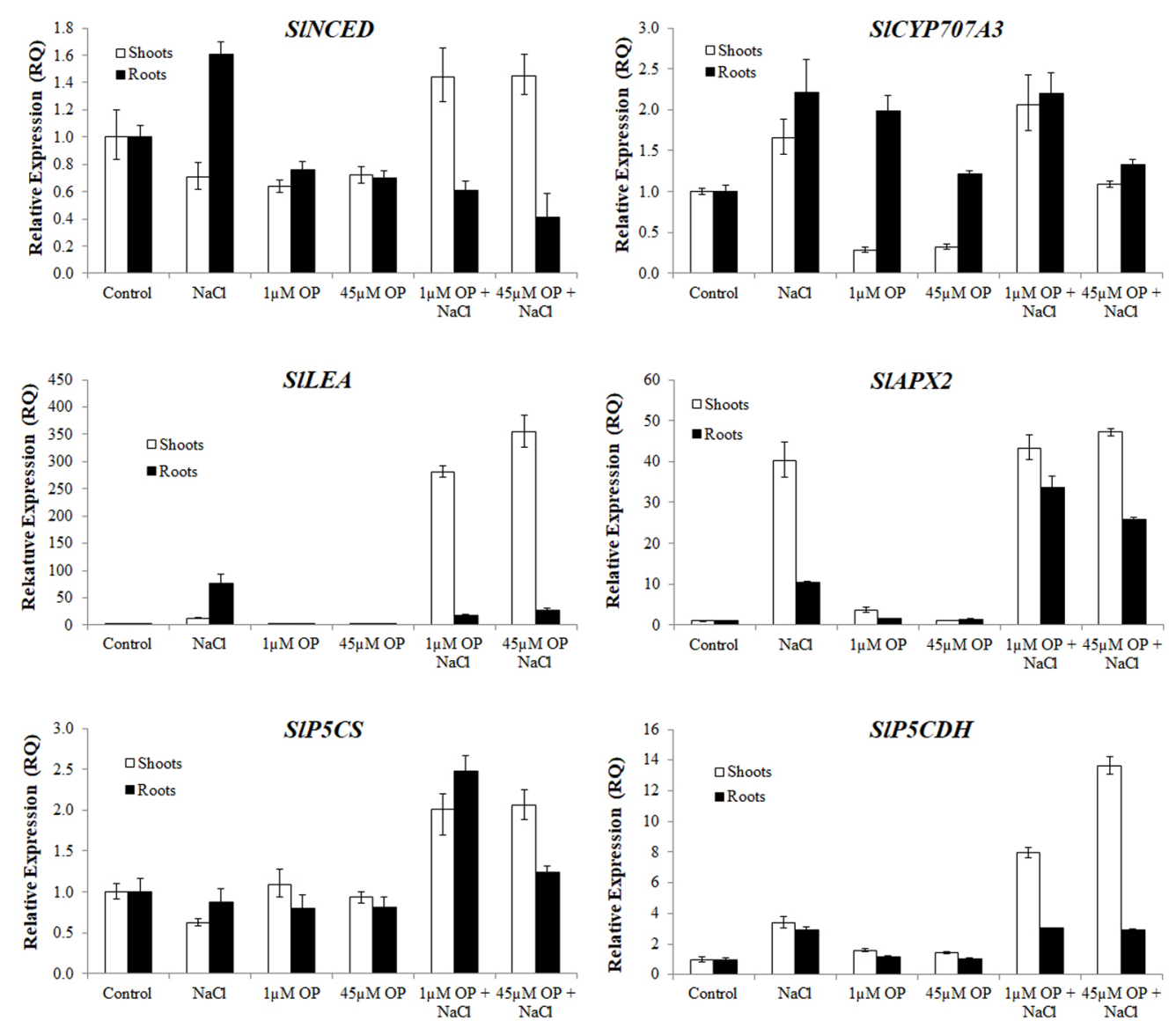

FIGURE 6 | Secondary metabolism and stress signaling gene expression in plants treated with omeprazole. Plants were grown in a hydroponic solution containing 0 , 1, and $45 \mu \mathrm{M}$ OP, with and without $200 \mathrm{mM} \mathrm{NaCl}$. Samples for qRT-PCR were harvested after 2 weeks of salt treatment (50 DAS, 14 DSS) and harvested for ion analysis. Values indicate average $\pm \operatorname{SD}(n=3)$.

increased by $55 \%$ and DW by $56 \%$ in the absence of stress. Under saline stress, shoot growth was maintained, with a $56 \%$ increase in shoot FW and 54\% increase in DW. Roots showed the most dramatic phenotype under salt stress, with a doubling of FW and DW over untreated controls (Figures 1, 2). Although this morphological change was not the only component that may have enhanced salt tolerance of OP treated plants, this response may have important implications with respect to growth and adaptation in saline environments (Julkowska et al., 2014; Feng et al., 2016). Longer, more extensive roots may help to escape salinization by exploring non salinized areas of the soil profile (De Pascale et al., 2012; Lynch et al., 2014; Feng et al., 2016; Annunziata et al., 2017). OP seems also to interfere with ABA responses. Lateral root formation is highly sensitive to $\mathrm{ABA}$ concentrations, with inhibition of lateral root primordia being an order of magnitude more sensitive than seed germination (De Smet et al., 2003). While ABA deficient mutants have impaired growth, endogenous ABA levels have been clearly shown to be inhibitory to root growth at low osmotic potentials (Sharp et al., 2004; Duan et al., 2013; Zhao et al., 2014). The effects of OP on lateral root formation are likely due to changes in ABA biosynthesis, catabolism, and/or perception. By decreasing biosynthesis of $\mathrm{ABA}$ in roots under salt stress and increasing catabolism, OP may overcome its inhibitory effects on root growth under low osmotic potential. These results also shed some light on the role of root systems in plant salt stress adaptation.

\section{Omeprazole Has Multiple Effects on Cellular Mechanisms That Enhance Salt Stress Tolerance}

Hyperaccumulation of $\mathrm{Na}^{+}$in the cytoplasm during salinity stress results in toxicity and disturbs essential cellular metabolisms such as protein synthesis, enzyme activity, and photosynthesis (Maggio et al., 2006; Hasegawa, 2013). Glycophytes cope with salinity stress by maintaining low cytosolic $\mathrm{Na}^{+}$levels and by acquisition and maintenance of $\mathrm{K}^{+}$ (Flowers and Colmer, 2015). Sodium exclusion and potassium uptake are essential adaptations in response to high salinity in the environment that improve salt tolerance. OP appears to augment these adaptive mechanisms by affecting the regulation of a number of ion transporters. Under OP, increased expression of SISOS1, SINHX1, and SINHX2 (Figure 5) establishes a 

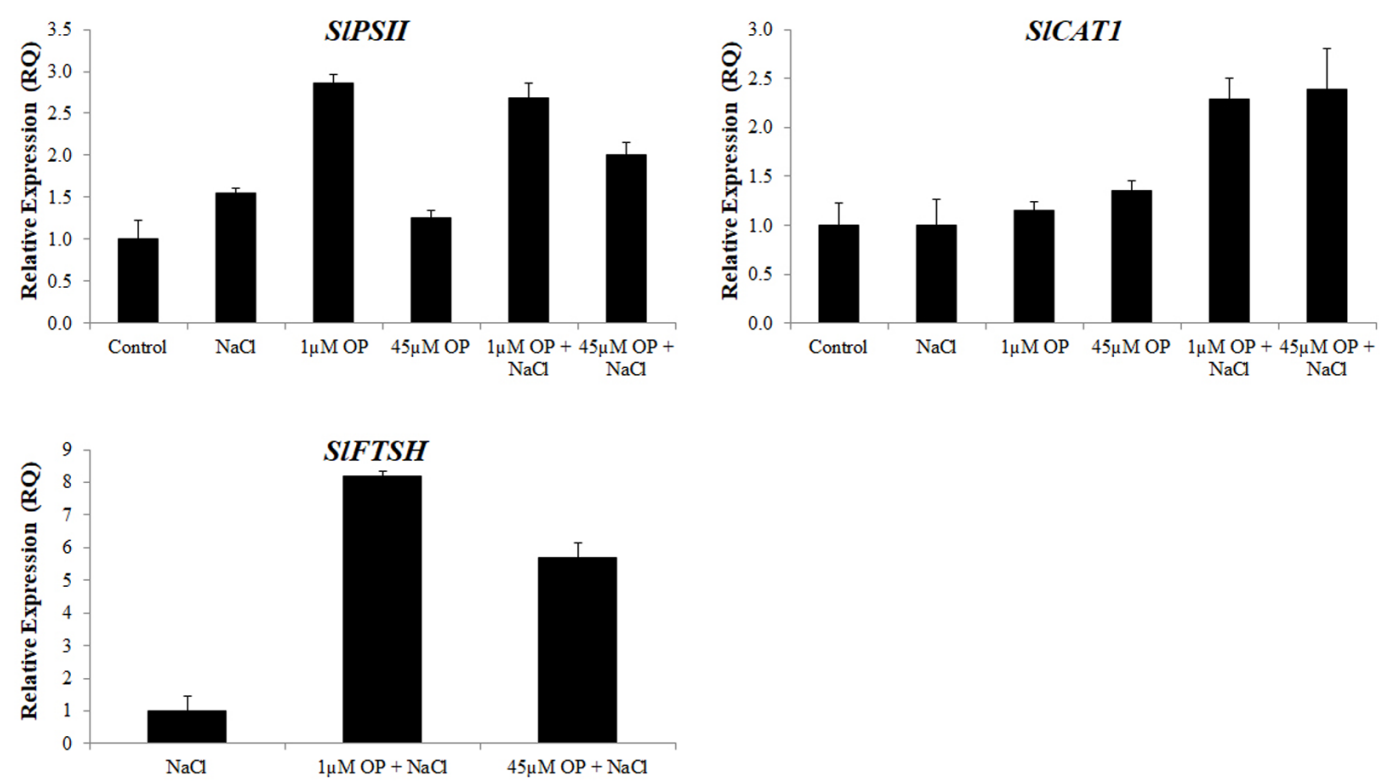

FIGURE 7 | Photosynthetic gene expression in plants treated with omeprazole. Plants were grown in a hydroponic solution containing 0,1 , and $45 \mu \mathrm{M}$ OP, with and without $200 \mathrm{mM} \mathrm{NaCl}$. Samples from leaves for qRT-PCR were harvested after 2 weeks of salt treatment (50 DAS, 14 DSS) and harvested for ion analysis. Values indicate average $\pm \operatorname{SD}(n=3)$.

pattern of sodium exclusion and increased potassium uptake, a result that was confirmed by the ion analysis (Figure 3). The plasma membrane sodium antiporter SOS1 is essential for excluding sodium from the cytoplasm and a key component in maintaining ion homeostasis (Ji et al., 2013). Similarly, NHX1 and NHX2 have been shown to enable maintenance of turgor, ion homeostasis, stomatal movements, growth regulation, cell expansion, and potassium uptake (Bassil et al., 2011; Barragán et al., 2012). In Arabidopsis, NXH1 selectivity has been associated to vacuolar calcium concentrations (Yamaguchi et al., 2005). The low concentrations of calcium found in shoot of OP treated plants at 1 and $10 \mu \mathrm{M}$ may have likely been correlated to a reduced calcium entry into the roots and consequently to effects on the selectivity of NHX1, as confirmed by the low $\mathrm{Na}^{+}: \mathrm{K}^{+}$ratio of root and shoot of OP treated plants (Figure 3). The expression pattern of SIHKT1.1 we found in root and shoot of OP treated plants is also of particular relevance. The dysregulation of SIHKT1.1 under salt stress and OP, with (1) increased expression in shoots to facilitate sodium recirculation to the roots and (2) decreased expression in roots to reduce sodium loading into the xylem and subsequent transport to sensitive photosynthetic tissues indicates that OP treatment augments the plant's ability to control sodium accumulation in sensitive tissues (Figure 5). HKT transporters play an important role in limiting the influx of sodium into the shoot and subsequent accumulation as well as sodium loading into root xylem (Hauser and Horie, 2010; Ali et al., 2016). High sodium shoot accumulation has been linked to low AtHKT1.1 expression in roots in a number of Arabidopsis ecotypes (Rus et al., 2006). HKT1 transporters and non-selective cation channels (NSCCs) are the major contributors to sodium uptake in cells (Hasegawa, 2013). Decreasing the expression of HKT1 transporters in roots, while increasing HKT1 expression in shoots, could therefore be a key consequence of OP activity in plants under salt stress. Based on the ion profiles, it is clear that the phenotype of salt stress tolerance seen under OP treatment is due in part to a re-partitioning of ions under stress conditions. The increased expression of SINRT1.1 (Figure 5) and the increased nitrate content in roots (Figure 3) indicate that OP may contribute to nitrogen uptake efficiency and resultant improvement in plant nutritional status. OP treated plants have a growth phenotype (Figures 1,2) and increased nitrogen uptake would certainly contribute to increased growth in ideal conditions.

\section{OP Protects the Photosynthetic System}

The reduction of $\mathrm{A}, \mathrm{g}_{\mathrm{s}} \Phi_{\mathrm{PSII}}$ and $\mathrm{qP}$ in non OP and OP treated plants exposed to $150 \mathrm{mM}$ of $\mathrm{NaCl}$ compared to the $0 \mathrm{NaCl}$ treatments indicated that salt stress reduced the efficiency of PSII reaction centers and impaired electron transport in the photosynthetic apparatus (Maxwell and Johnson, 2000; Baker, 2008). OP treatment seemed to improve the actual quantum yield of PSII ( $\left.\Phi_{\text {PSII }}\right)$ and the photochemical quenching $(\mathrm{qP})$ in the salt stressed leaves. We found that a number of key photosynthesis genes involved in photosystem II repair and ROS scavenging were upregulated under OP treatment (Figures 6, 7). Expression of catalase is a clear indicator of increased ROS scavenging and removal of potentially harmful accumulation of $\mathrm{H}_{2} \mathrm{O}_{2}$ (Mittova et al., 2000; Das and Roychoudhury, 2014). The upregulation under OP treatment of two key components of photosystem II repair, SIPSII and SIFTSH, seems to indicate that while salt stress does damage the photosystem, repair mechanisms required to 
maintain a nominal level of photosynthesis are less impeded. Transcript and protein accumulation of low molecular mass proteins (PSII like) have been observed in response to ROS and abiotic stress (Hihara et al., 2003; Kosmala et al., 2009; Shi et al., 2012). Arabidopsis mutants of SIPSII and SIFTSH genes show a decreased capacity for photosynthesis under abiotic stress (Sun et al., 2007) and in tomato, SIFTSH content is decreased after drought stress (Tamburino et al., 2017). The decreased expression of a key rate-limiting step of ABA biosynthesis in OP roots and shoots indicates that ABA levels are likely altered under OP treatment. More importantly, roots and shoots respond very differently under OP treatment, in the presence of salt stress. ABA responses under OP and salt treatment appear to be upregulated in shoots while at the same time, downregulated in roots. This is observed in the expression of SINCED, SlCYP707A3, and the ABA responsive SILEA gene. One possible explanation for this gene expression profile and observed growth phenotype under salt stress is that OP inhibited root $\mathrm{ABA}$ biosynthesis and activated shoot $\mathrm{ABA}$ biosynthesis which would allow root growth and branching under stress conditions (normally inhibited by ABA) (Sharp and LeNoble, 2002) and control ethylene production in the shoot which would otherwise inhibit growth (Sharp, 2002). This hypothesis could also be aligned with the expression levels of SIP5CS and SIP5CDH genes that may have contributed to an increased accumulation of proline in the roots, a response that typically, but not always, follows high ABA levels (Mattioli et al., 2009; Barbieri et al., 2012).

\section{Possible Targets of Omeprazole in Plants}

At the moment we do not have yet conclusive evidence for the molecular target(s) of OP. The OP concentrations we used and dose responses indicate that OP acts with a hormone-like behavior with growth stimulation between 1 and $10 \mu \mathrm{M}$ and inhibitory effects at higher concentrations (Figures 1, 2). Similar responses have been reported for other molecules including phytohormones (Bartoli et al., 2013; Huot et al., 2014; LozanoDurán and Zipfel, 2015). However, only for a few of these single-molecule effectors a function on growth enhancement and stress tolerance has been demonstrated. Plants lack TypeIIC ATPases that transport $\mathrm{K}^{+}$and $\mathrm{Na}^{+}$, the known target of OP, and the closest related classes of ATPases in plants share very low homology with animal $\mathrm{H}^{+} / \mathrm{K}^{+}$-ATPase (Sweadner and Donnet, 2001). However, based on the well-characterized function as $\mathrm{H}^{+} / \mathrm{K}^{+}$-ATPase inhibitor in animal systems, we can

\section{REFERENCES}

Ali, A., Raddatz, N., Aman, R., Kim, S., Park, H. C., Jan, M., et al. (2016). A single amino-acid substitution in the sodium transporter HKT1 associated with plant salt tolerance. Plant Physiol. 171, 2112-2126. doi: 10.1104/pp.16.00569

Al-Taweel, K., Iwaki, T., Yabuta, Y., Shigeoka, S., Murata, N., and Wadano, A. (2007). A bacterial transgene for catalase protects translation of D1 protein during exposure of salt-stressed tobacco leaves to strong light. Plant Physiol. 145, 258-265. doi: 10.1104/pp.107.101733

Altshuler, I., Vaillant, J. J., Xu, S., and Cristescu, M. E. (2012). The Evolutionary History of Sarco(endo)plasmic Calcium ATPase (SERCA). PLoS ONE 7:e52617. doi: 10.1371/journal.pone.0052617 also hypothesize that OP is inhibiting an ATPase present in plants. This hypothesis is difficult to come to terms with, since very little room exists in our current paradigm of ATPase driven proton gradients and ion transport, where inhibition of one or more of these components would actually increase growth or tolerance to salinity. Ion homeostasis is key to growth and adaptation to osmotic stress, a clear mechanism for the role of OP does not readily present itself. The possibility that OP is exerting its effect through a mechanism of action which is unrelated to an ATPase inhibitory function in plants should also be considered. OP appears to be one of a few molecules with a dual function of growth enhancer and stress protectant and it represents an excellent candidate to explore key mechanisms that could shed some light on how plant growth inhibition and adaptation in response to salt stress can be uncoupled (Ruggiero et al., 2004). While the exact target of omeprazole remains unclear, the physiological effects open new avenues for understanding the mechanisms that allow plants to grow under adverse conditions.

\section{AUTHOR CONTRIBUTIONS}

MVO wrote the paper and did most of the experimental work. SS contributed to plant growth analyses and molecular characterization. GG made the gas exchange measurements and fluorescence analysis. VC and EDS worked on the statistical analysis. PC and PW worked on ion analysis and contributed to writing. AM wrote the paper together with MVO and coordinated the research work. GR had the original idea on testing omeprazole on plants and contributed to data analysis.

\section{ACKNOWLEDGMENT}

The authors would like to thank, in particular, Stefania Grillo and Giorgia Batelli of the CNR-IBBR for the use of their facilities and support in this work.

\section{SUPPLEMENTARY MATERIAL}

The Supplementary Material for this article can be found online at: http://journal.frontiersin.org/article/10.3389/fpls.2017.01220/ full\#supplementary-material

Annunziata, M. G., Ciarmiello, L. F., Woodrow, P., Maximova, E., Fuggi, A., and Carillo, P. (2017). Durum Wheat Roots Adapt to Salinity Remodeling the Cellular Content of Nitrogen Metabolites and Sucrose. Front. Plant Sci. 7:2035. doi: 10.3389/fpls.2016.02035

Aragüés, R., Medina, E. T., Zribi, W., Clavería, I., Álvaro-Fuentes, J., and Faci, J. (2015). Soil salinization as a threat to the sustainability of deficit irrigation under present and expected climate change scenarios. Irrig. Sci. 33, 67-79. doi: 10.1007/s00271-014-0449-x

Asins, M. J., Villalta, I., Aly, M. M., Olías, R., Álvarez De Morales, P., Huertas, R., et al. (2013). Two closely linked tomato HKT coding genes are positional candidates for the major tomato QTL involved in $\mathrm{Na}+/ \mathrm{K}+$ homeostasis. Plant Cell Environ. 36, 1171-1191. doi: 10.1111/pce.12051 
Axelsen, K. B., and Palmgren, M. G. (1998). Evolution of substrate specificities in the P-Type ATPase superfamily. J. Mol. Evol. 46, 84-101. doi: 10.1007/ PL00006286

Baker, N. R. (2008). Chlorophyll fluorescence: a probe of photosynthesis in vivo. Annu. Rev. Plant Biol. 59, 89-113. doi: 10.1146/annurev.arplant.59.032607. 092759

Barbieri, G., Vallone, S., Orsini, F., Paradiso, R., De Pascale, S., Negre-Zakharov, F., et al. (2012). Stomatal density and metabolic determinants mediate salt stress adaptation and water use efficiency in basil (Ocimum basilicum L.). J. Plant Physiol. 169, 1737-1746. doi: 10.1016/j.jplph.2012.07.001

Barragán, V., Leidi, E. O., Andrés, Z., Rubio, L., Luca, A. D., Fernández, J. A., et al. (2012). Ion exchangers NHX1 and NHX2 mediate active potassium uptake into vacuoles to regulate cell turgor and stomatal function in Arabidopsis. Plant Cell 24, 1127-1142. doi: 10.1105/tpc.111.095273

Bartoli, C. G., Casalongué, C. A., Simontacchi, M., Marquez-Garcia, B., and Foyer, C. H. (2013). Interactions between hormone and redox signalling pathways in the control of growth and cross tolerance to stress. Environ. Exp. Bot. 94, 73-88. doi: 10.1016/j.envexpbot.2012.05.003

Bassil, E., Tajima, H., Liang, Y.-C., Ohto, M., Ushijima, K., Nakano, R., et al. (2011). The Arabidopsis $\mathrm{Na}+/ \mathrm{H}+$ antiporters $\mathrm{NHX} 1$ and $\mathrm{NHX} 2$ control vacuolar $\mathrm{pH}$ and $\mathrm{K}+$ homeostasis to regulate growth, flower development, and reproduction. Plant Cell 23, 3482-3497. doi: 10.1105/tpc.111.089581

Batelli, G., Verslues, P. E., Agius, F., Qiu, Q., Fujii, H., Pan, S., et al. (2007). SOS2 promotes salt tolerance in part by interacting with the vacuolar $\mathrm{H}+$ ATPase and upregulating its transport activity. Mol. Cell. Biol. 27, 7781-7790. doi: 10.1128/MCB.00430-07

Baumann, M., and Baxendale, I. R. (2013). An overview of the synthetic routes to the best selling drugs containing 6-membered heterocycles. Beilstein J. Org. Chem. 9, 2265-2319. doi: 10.3762/bjoc.9.265

Carillo, P., Parisi, D., Woodrow, P., Pontecorvo, G., Massaro, G., Annunziata, M. G., et al. (2011). Salt-induced accumulation of glycine betaine is inhibited by high light in durum wheat. Funct. Plant Biol. 38, 139-150. doi: 10.1071/FP10177

Das, K., and Roychoudhury, A. (2014). Reactive oxygen species (ROS) and response of antioxidants as ROS-scavengers during environmental stress in plants. Front. Environ. Sci. 2:53. doi: 10.3389/fenvs.2014.00053

De Pascale, S., Orsini, F., Caputo, R., Palermo, M. A., Barbieri, G., and Maggio, A. (2012). Seasonal and multiannual effects of salinisation on tomato yield and fruit quality. Funct. Plant Biol. 39, 689-698. doi: 10.1071/FP12152

De Smet, I., Signora, L., Beeckman, T., Inzé, D., Foyer, C. H., and Zhang, H. (2003). An abscisic acid-sensitive checkpoint in lateral root development of Arabidopsis. Plant J. 33, 543-555. doi: 10.1046/j.1365-313X.2003. 01652.x

Deinlein, U., Stephan, A. B., Horie, T., Luo, W., Xu, G., and Schroeder, J. I. (2014). Plant salt-tolerance mechanisms. Trends Plant Sci. 19, 371-379. doi: 10.1016/j.tplants.2014.02.001

Duan, L., Dietrich, D., Ng, C. H., Chan, P. M. Y., Bhalerao, R., Bennett, M. J., et al. (2013). Endodermal ABA signaling promotes lateral root quiescence during salt stress in Arabidopsis seedlings. Plant Cell 25, 324-341. doi: 10.1105/tpc.112. 107227

FAO (2011). The State of the World's Land and Water Resources for Food and Agriculture (SOLAW) - Managing Systems at Risk. Rome: Food and Agriculture Organization of the United Nations.

Feng, W., Lindner, H., Robbins, N. E., and Dinneny, J. R. (2016). Growing out of stress: the role of cell- and organ-scale growth control in plant water-stress responses. Plant Cell 28, 1769-1782. doi: 10.1105/tpc.16.00182

Flowers, T. J., and Colmer, T. D. (2015). Plant salt tolerance: adaptations in halophytes. Ann. Bot. 115, 327-331. doi: 10.1093/aob/mcu267

Genty, B., Harbinson, J., and Baker, N. R. (1990). Relative quantum efficiencies of the two-photosystems of leaves in photorespiratory and non-photorespiratory conditions. Plant Physiol. Biochem. 28, 1-10.

Hasegawa, P. M. (2013). Sodium (Na+) homeostasis and salt tolerance of plants. Environ. Exp. Bot. 92, 19-31. doi: 10.1016/j.envexpbot.2013.03.001

Hauser, F., and Horie, T. (2010). A conserved primary salt tolerance mechanism mediated by HKT transporters: a mechanism for sodium exclusion and maintenance of high $\mathrm{K}+/ \mathrm{Na}+$ ratio in leaves during salinity stress. Plant Cell Environ. 33, 552-565. doi: 10.1111/j.1365-3040.2009.02056.x

Hihara, Y., Sonoike, K., Kanehisa, M., and Ikeuchi, M. (2003). DNA microarray analysis of redox-responsive genes in the genome of the cyanobacterium
Synechocystis sp. Strain PCC 6803. J. Bacteriol. 185, 1719-1725. doi: 10.1128/ JB.185.5.1719-1725.2003

Huot, B., Yao, J., Montgomery, B. L., and He, S. Y. (2014). Growth-defense tradeoffs in plants: a balancing act to optimize fitness. Mol. Plant 7, 1267-1287. doi: $10.1093 / \mathrm{mp} / \mathrm{ssu} 049$

Iovieno, P., Punzo, P., Guida, G., Mistretta, C., Van Oosten, M. J., Nurcato, R., et al. (2016). Transcriptomic changes drive physiological responses to progressive drought stress and rehydration in tomato. Front. Plant Sci. 7:371. doi: 10.3389/ fpls.2016.00371

Ji, H., Pardo, J. M., Batelli, G., Van Oosten, M. J., Bressan, R. A., and Li, X. (2013). The salt overly sensitive (SOS) pathway: established and emerging roles. Mol. Plant 6, 275-286. doi: 10.1093/mp/sst017

Jossier, M., Kroniewicz, L., Dalmas, F., Le Thiec, D., Ephritikhine, G., Thomine, S., et al. (2010). The Arabidopsis vacuolar anion transporter, AtCLCc, is involved in the regulation of stomatal movements and contributes to salt tolerance. Plant J. 64, 563-576. doi: 10.1111/j.1365-313X.2010.04352.x

Julkowska, M. M., Hoefsloot, H. C. J., Mol, S., Feron, R., de Boer, G.-J., Haring, M. A., et al. (2014). Capturing Arabidopsis root architecture dynamics with root-fit reveals diversity in responses to salinity. Plant Physiol. 166, 1387-1402. doi: $10.1104 /$ pp.114.248963

Kato, Y., Miura, E., Ido, K., Ifuku, K., and Sakamoto, W. (2009). The variegated mutants lacking chloroplastic FtsHs are defective in D1 degradation and accumulate reactive oxygen species. Plant Physiol. 151, 1790-1801. doi: 10.1104/ pp.109.146589

Kosmala, A., Bocian, A., Rapacz, M., Jurczyk, B., and Zwierzykowski, Z. (2009). Identification of leaf proteins differentially accumulated during cold acclimation between Festuca pratensis plants with distinct levels of frost tolerance. J. Exp. Bot. 60, 3595-3609. doi: 10.1093/jxb/erp205

Lal, R. (2015). Restoring soil quality to mitigate soil degradation. Sustainability 7 , 5875-5895. doi: 10.3390/su7055875

Li, J., Jia, H., Wang, J., Cao, Q., and Wen, Z. (2014). Hydrogen sulfide is involved in maintaining ion homeostasis via regulating plasma membrane $\mathrm{Na}+/ \mathrm{H}+$ antiporter system in the hydrogen peroxide-dependent manner in salt-stress Arabidopsis thaliana root. Protoplasma 251, 899-912. doi: 10.1007/s00709-0130592-x

Li-Cor (2011). Using the LI-6400/LI-6400XT Portable Photosynthesis System, 10th Edn. Lincoln, NE: LI-COR, Inc.

Lozano-Durán, R., and Zipfel, C. (2015). Trade-off between growth and immunity: role of brassinosteroids. Trends Plant Sci. 20, 12-19. doi: 10.1016/j.tplants.2014. 09.003

Lynch, J. P., Chimungu, J. G., and Brown, K. M. (2014). Root anatomical phenes associated with water acquisition from drying soil: targets for crop improvement. J. Exp. Bot. 65, 6155-6166. doi: 10.1093/jxb/ eru 162

Maggio, A., Zhu, J.-K., Hasegawa, P. M., and Bressan, R. A. (2006). Osmogenetics: Aristotle to Arabidopsis. Plant Cell 18, 1542-1557. doi: 10.1105/tpc.105. 040501

Mancarella, S., Orsini, F., Van Oosten, M. J., Sanoubar, R., Stanghellini, C., Kondo, S., et al. (2016). Leaf sodium accumulation facilitates salt stress adaptation and preserves photosystem functionality in salt stressed Ocimum basilicum. Environ. Exp. Bot. 130, 162-173. doi: 10.1016/j.envexpbot.2016. 06.004

Mattioli, R., Costantino, P., and Trovato, M. (2009). Proline accumulation in plants. Plant Signal. Behav. 4, 1016-1018. doi: 10.4161/psb.4.11.9797

Maxwell, K., and Johnson, G. N. (2000). Chlorophyll fluorescence-a practical guide. J. Exp. Bot. 51, 659-668. doi: 10.1093/jexbot/51.345.659

McTavish, D., Buckley, M. M., and Heel, R. C. (1991). Omeprazole. An updated review of its pharmacology and therapeutic use in acid-related disorders. Drugs 42, 138-170. doi: 10.2165/00003495-199142010-00008

Mills, R. F., Doherty, M. L., López-Marqués, R. L., Weimar, T., Dupree, P., Palmgren, M. G., et al. (2008). ECA3, a golgi-localized P2A-Type ATPase, plays a crucial role in manganese nutrition in Arabidopsis. Plant Physiol. 146, 116-128. doi: 10.1104/pp.107.110817

Mittova, V., Volokita, M., Guy, M., and Tal, M. (2000). Activities of SOD and the ascorbate-glutathione cycle enzymes in subcellular compartments in leaves and roots of the cultivated tomato and its wild salt-tolerant relative Lycopersicon pennellii. Physiol. Plant. 110, 42-51. doi: 10.1034/j.1399-3054.2000. 110106.x 
Pardo, J. M., Cubero, B., Leidi, E. O., and Quintero, F. J. (2006). Alkali cation exchangers: roles in cellular homeostasis and stress tolerance. J. Exp. Bot. 57, 1181-1199. doi: 10.1093/jxb/erj114

Park, H. J., Kim, W.-Y., and Yun, D.-J. (2016). A new insight of salt stress signaling in plant. Mol. Cells 39, 447-459. doi: 10.14348/molcells.2016.0083

Rengasamy, P. (2006). World salinization with emphasis on Australia. J. Exp. Bot. 57, 1017-1023. doi: 10.1093/jxb/erj108

Ruggiero, B., Koiwa, H., Manabe, Y., Quist, T. M., Inan, G., Saccardo, F., et al. (2004). Uncoupling the effects of abscisic acid on plant growth and water relations. Analysis of sto1/nced3, an abscisic acid-deficient but salt stresstolerant mutant in Arabidopsis. Plant Physiol. 136, 3134-3147. doi: 10.1104/ pp.104.046169

Rus, A., Baxter, I., Muthukumar, B., Gustin, J., Lahner, B., Yakubova, E., et al. (2006). Natural variants of AtHKT1 enhance $\mathrm{Na}+$ accumulation in two wild populations of Arabidopsis. PLoS Genet. 2:e210. doi: 10.1371/journal.pgen. 0020210

Sharp, R. E. (2002). Interaction with ethylene: changing views on the role of abscisic acid in root and shoot growth responses to water stress. Plant Cell Environ. 25, 211-222. doi: 10.1046/j.1365-3040.2002.00798.x

Sharp, R. E., and LeNoble, M. E. (2002). ABA, ethylene and the control of shoot and root growth under water stress. J. Exp. Bot. 53, 33-37. doi: 10.1093/jxb/53. 366.33

Sharp, R. E., Poroyko, V., Hejlek, L. G., Spollen, W. G., Springer, G. K., Bohnert, H. J., et al. (2004). Root growth maintenance during water deficits: physiology to functional genomics. J. Exp. Bot. 55, 2343-2351. doi: 10.1093/jxb/erh276

Shen, G., Wei, J., Qiu, X., Hu, R., Kuppu, S., Auld, D., et al. (2015). Cooverexpression of AVP1 and AtNHX1 in cotton further improves drought and salt tolerance in transgenic cotton plants. Plant Mol. Biol. Rep. 33, 167-177. doi: 10.1007/s11105-014-0739-8

Shi, L.-X., Hall, M., Funk, C., and Schröder, W. P. (2012). Photosystem II, a growing complex: updates on newly discovered components and low molecular mass proteins. Biochim. Biophys. Acta 1817, 13-25. doi: 10.1016/j.bbabio.2011.08.008

Shin, J. M., Munson, K., Vagin, O., and Sachs, G. (2009). The gastric HK-ATPase: structure, function, and inhibition. Pflugers. Arch. 457, 609-622. doi: 10.1007/ s00424-008-0495-4

Sun, X., Fu, T., Chen, N., Guo, J., Ma, J., Zou, M., et al. (2010). The stromal chloroplast Deg7 protease participates in the repair of photosystem II after photoinhibition in Arabidopsis. Plant Physiol. 152, 1263-1273. doi: 10.1104/pp. 109.150722

Sun, X., Wang, L., and Zhang, L. (2007). Involvement of DEG5 and DEG8 proteases in the turnover of the photosystem II reaction center D1 protein under heat stress in Arabidopsis thaliana. Chin. Sci. Bull. 52, 1742-1745. doi: 10.1007/ s11434-007-0275-0
Sweadner, K. J., and Donnet, C. (2001). Structural similarities of Na,K-ATPase and SERCA, the $\mathrm{Ca}(2+)$-ATPase of the sarcoplasmic reticulum. Biochem. J. 356, 685-704. doi: 10.1042/bj3560685

Tamburino, R., Vitale, M., Ruggiero, A., Sassi, M., Sannino, L., Arena, S., et al. (2017). Chloroplast proteome response to drought stress and recovery in tomato (Solanum lycopersicum L.). BMC Plant Biol. 17:40. doi: 10.1186/s12870017-0971-0

Van Oosten, M. J., Costa, A., Punzo, P., Landi, S., Ruggiero, A., Batelli, G., et al. (2016). "Genetics of drought stress tolerance in crop plants," in Drought Stress Tolerance in Plants, Vol. 2, eds M. A. Hossain, S. H. Wani, S. Bhattacharjee, D. J. Burritt, and L.-S. P. Tran (Basel: Springer International Publishing), 39-70.

von Caemmerer, S., and von Farquhar, G. D. (1981). Some relationships between the biochemistry of photosynthesis and the gas exchange of leaves. Planta 153, 376-387. doi: 10.1007/BF00384257

Wallmark, B. (1986). Mechanism of action of omeprazole. Scand. J. Gastroenterol. Suppl. 118, 11-17. doi: 10.3109/00365528609090881

Yamaguchi, T., Aharon, G. S., Sottosanto, J. B., and Blumwald, E. (2005). Vacuolar $\mathrm{Na}+/ \mathrm{H}+$ antiporter cation selectivity is regulated by calmodulin from within the vacuole in a Ca2+- and pH-dependent manner. Proc. Natl. Acad. Sci. U.S.A. 102, 16107-16112. doi: 10.1073/pnas.0504437102

Yoo, C. Y., Pence, H. E., Jin, J. B., Miura, K., Gosney, M. J., Hasegawa, P. M., et al. (2010). The Arabidopsis GTL1 transcription factor regulates water use efficiency and drought tolerance by modulating stomatal density via transrepression of SDD1. Plant Cell 22, 4128-4141. doi: 10.1105/tpc.110.078691

Zhang, H.-X., and Blumwald, E. (2001). Transgenic salt-tolerant tomato plants accumulate salt in foliage but not in fruit. Nat. Biotechnol. 19, 765-768. doi: $10.1038 / 90824$

Zhao, Y., Xing, L., Wang, X., Hou, Y.-J., Gao, J., Wang, P., et al. (2014). The ABA receptor PYL8 promotes lateral root growth by enhancing MYB77-dependent transcription of auxin-responsive genes. Sci. Signal. 7:ra53. doi: $10.1126 /$ scisignal.2005051

Conflict of Interest Statement: The authors declare that the research was conducted in the absence of any commercial or financial relationships that could be construed as a potential conflict of interest.

Copyright (c) 2017 Van Oosten, Silletti, Guida, Cirillo, Di Stasio, Carillo, Woodrow, Maggio and Raimondi. This is an open-access article distributed under the terms of the Creative Commons Attribution License (CC BY). The use, distribution or reproduction in other forums is permitted, provided the original author(s) or licensor are credited and that the original publication in this journal is cited, in accordance with accepted academic practice. No use, distribution or reproduction is permitted which does not comply with these terms. 